\title{
TARIAN DADAS DALAM PEMBENTUKAN KARAKTER DISIPLIN ANAK PADA SANGGAR IGAL JUE PALANGKA RAYA
}

\author{
Eriska Leluni ${ }^{1}$, Offeny ${ }^{2}$, Sakman $^{3}$ \\ 1,2,3 Jl. Sangga buana ii, Universitas Palangka Raya \\ E-mail :eriskahawinu@gmail.com ${ }^{1}$,offeny.pky58@gmail.com², triyani@fkip.upr.ac.id ${ }^{3}$
}

\begin{abstract}
Abstrak :
Penelitian ini bertujuan untuk melihat makna tarian dadas dalam membentuk karakter disiplin anak pada sanggar Igal Jue Kota Palangka Raya. Metode penelitian menggunakan Pendekatan penelitian yang digunakan dalam penelitian adalah kualitatif deskriptif karena dalam penelitian ini menghasilkan kesimpulan berupa data yang menggambarkan secara rinci, bukan data yang berupa angka-angka. Penelitian kualitatif adalah suatu pendekatan ilmiah yang mengungkap situasi sosial tertentu dengan mendeskripsikan kenyataan secara benar, dibentuk oleh kata-kata berdasarkan teknik pengumpulan analisis data yang relevan yang diperoleh dari situasi yang alamiah. Hasil penelitian menunjukan bahwa makna tarian dadas dalam membentuk karakter disiplin yang melakuklan tarian dadas disitu sudah tentu jika tidak disiplin dalam melakukan latihan tarian itu tidak bisa dilakukan harus mempunyai konsentari yang tinggi dalam menari untuk menyesuaikan irama dan gerak sehingga mau tidak mau anak sanggar secara tidak langsung melatih karakter disiplin dalam melakukan latihan. Nilai-nilai yang terkandung dalam tarian dadas adalah nilai magis, nilai seni budaya, nilai pesan sejarah, nilai karakter dan nilai estetika keindahan dan keunikan dalam tarian dan musik. Sehingga penari tarian dadas haru mempunyai sikap dan karakter yang baik sehat jasmani dan rohani jika tidak maka, kesan lain bisa masuk karena mempunyai nilai - nilai megis. Faktor pendukung pemebentukan karakter disiplin adalah jadwal yang di buat dan disepakati bersama sebab setiap anggota tim, harus disiplin waktu dan juga mempunyai komitmen. Kemudian faktor penghambat ketika ada anggota yang tidak disiplin dan sulit menghapal karakter yang ia pegang serta gerakan dan kesesuaian anatara gerak dan musik.
\end{abstract}

Kata Kunci: Tarian Dadas; Pembentukan Karakter Disiplin; Anak

\begin{abstract}
:
Problems discussed by Dadas Dance in Forming Disciplinary Character of Children in Jgal Palangka Raya Studio Igal. This study aims to determine the Dadas Dance in the Formation of Disciplinary Characters of Children in Jgal Palangka Raya Studio Igal. The method used is a
\end{abstract}


qualitative method. The research instruments are included: observation sheets, interview, literature study, documentation. The results of the research that the meaning of dadas dance in shaping the character of discipline that performs dadas dance there, of course, if it is not disciplined in doing dance exercises it cannot be done, must have a high concentration in dancing to adjust the rhythm and motion so that inevitably the studio children indirectly train the studio disciplined character in conducting exercises. The values contained in dadas dance are magical values, cultural art values, historical message values, character values and aesthetic values of beauty and uniqueness in dance and music. So that the dancer dances must have good attitude and character, physically and mentally healthy, if not then, another impression can come in because it has megis values. Factors supporting the formation of discipline character are schedules that are made and mutually agreed upon because each team member must be disciplined in time and also committed. Then the inhibiting factor when there are members who are undisciplined and difficult to memorize the character that he holds and the movement and suitability between motion and music.

Keywords: Dadas dance; Disciplinary Character; Children

\section{A. PENDAHULUAN}

Latar Belakang Bangsa Indonesia adalah bangsa yang mempunyai berbagai macam seni budaya yang berkembang di dalam masyarakatnya(Karliani, Lion, \& Sakman, 2018). Banyaknya jenis ragam seni budaya yang ada dan berkembang dalam masyarakat menggambarkan kekayaan ragam seni budaya Indonesia (Eva Isdayanti, 2020). Ragam seni budaya tersebut meliputi kebudayaan asli Indonesia yang tersebar di daerah-daerah seluruh wilayah Indonesia dan masih bersifat tradisional. Sekarang ini kita telah masuk dalam arus modernisasi, di mana kita dihadapkan dengan masuknya berbagai kemajuan di berbagai bidang, seperti politik, ekonomi, sosial, budaya, dan iptek.

Tujuan Secara umum penelitian ini bertujuan untuk mengumpulkan data memecahkan setiap masalah yang ditemukakn dalam penelitian ini. Secara khusus, penelitian ini bertujuan untuk mendeskripsi dan menganalisis bagai mana tarian dadas dalam pembentukan karakter disiplin anak pada sanggar Igal Jue Palangka Raya. Untuk mendeskripsi dan menganalisis bagai mana nilai-nilai yang terkandung dalam tarian dadas dalam pembentukan karakter disiplin pada Sanggar Igal Jue Palangka Raya. Untuk mendeskripsi dan menganalisis apajakah faktor pendukung dan penghambat pembentukan karakter disiplin anak pada sanggar Igal Jue Palangka Raya.

\section{B. KAJIAN TEORI}

Seni tari yaitu seni yang dilakukan di tempat dan waktu tertentu menggunakan gerakan tubuh secara berirama untuk keperluan mengungkapkan maksud, pikiran, dan perasaan manusia didalam dirinya yang mendorongnya untuk mencari ungkapan berupa gerak ritmis(Suwaji, 2012). Unsur dasar tari yaitu bentuk gerak tari yang melibatkan anggota tubuh yang dapat berdiri sendiri atau bersambungan. Ada banyak unsur pendukung atau pelengkap dalam tari antara lain tema, tempat pentas/panggung, iringan musik, tata rias, tata busana, dan tata lampu/sinar serta tata suara(Restuningrum, 2017). Empat aspek dalam unsur dasar tari, antara lain: Wiraga, Wirama, Wirasa , Wirupa.

\section{Penggolongan Tari}

Paris Langkis 
Menurut (Siswandi, 2006:64) latar belakang kemunculan seni tari di Indonesia terbagi menjadi tiga antara lain: Tari Daerah (Tari Rakyat) Tarian yang lahir dari masyarakat biasa sebagai lambang kegembiraan dan rasa suka cita. Tarian yang lahir dari kebudayaan lokal. Tarian ini menjadi tradisi, karena kebiasaan masyarakat sekitar yang merasakan suka cita bersama berkumpul merayakan dan menari. Tari Tradisional (Tari Klasik) Tarian yang lahir dari kaum bangsawan atau dari dalam keraton dan lahir pada zaman raja-raja. Tarian jenis ini hanya berkembang di lingkungan tertentu, bahkan masyarakat biasa dilarang menarikannya. Tari Kreasi Baru (Modern) Tarian kreasi baru ini tarian yang tidak terikat aturan-aturan tradisi atau daerah tertentu. Tarian ini diolah dengan konsep dan ide yang baru sesuai dengan unsur yang ada. Unsur tersebut adalah gerak tubuh (sebagian atau keseluruhannya), ritme (irama), bentuk (pola), dan ruang (space)(Nursyam, Nasution, Yeni, \& Anggraini, 2016).

\section{Jenis dan Fungsi Seni}

Beberapa jenis dan fungsi tari yang digunakan oleh masyarakat, menurut Jazuli (1994:43-46) adalah sebagai berikut. Tari untuk Sarana Upacara keagamaan yaitu jenis tari-tarian yang digunakan dalam peristiwa keagamaan. Jenis tarian semacam ini masih bisa dilihat di pulau Bali sebagai pusat perkembangan agama Hindu(Ni Made, 2015). Jenis tarian ini diselenggarakan di Pura-Pura pada waktu tertentu dan merupakan tarian sesaji yang bersifat religius. Tari Sebagai Hiburan lebih menitik beratkan pada pemberian kepuasan perasaan tanpa mempunyai tujuan yang lebih dalam seperti memperoleh pengetahuan dan pengalaman dari apa yang dilihatnya. Tari sebagai pertunjukan mengandung pengertian untuk mempertunjukkan sesuatu yang dinilai seni, tetapi senantiasa berusaha untuk menarik perhatian dan dapat memberikan kepuasan sejauh aspek jiwa melibatkan diri dalam pertunjukan itu dan memperoleh kesan setelah dinikmati sehingga menimbulkan adanya perubahan dan wawasan baru. Tari Sebagai Media Pendidikan seni merupakan pendidikan sikap estetis guna membantu membentuk manusia seutuhnya dan selaras dengan perkembangan pribadi yang memperhatikan lingkungan sosial, budaya dan hubungan dengan Tuhan.

\section{Tentang Tari Balian Dadas}

Tari Balian Dadas adalah tarian tradisional yang berasal dari suku Dayak yang ada di Provinsi Kalimantan Tengah(Riantri, 2019). Tari ini berasal dari tradisi ritual dukun di pedalaman Kalimantan Tengah dalam upaya meminta keberkahan tuhan dan penyembuhan bagi penduduk yang sakit. Tari Balian Dadas merupakan tari pelengkap dalam ritual penyembuhan masyarakat Dayak, namun seiring perkembangan zaman banyak muda mudi yang belajar tari Balian dadas sebagai sara hiburan dan melestarikan eksistensi tari Balian Dadas ini. Pada saat ini tari Balian Dadas ditampilkan dalam pada acara adat dan acara pemerintahan seperti pada saat penyambutan.

Sejarah Wadian dadas adalah salah satu sarana upacara dalam bidang pengobatan tradisional pada masyarakat Suku Dayak Ma'nyan di Kecamatan Dusun Utara, Kabupaten Barito Selatan Provinsi Kalimantan Tengah. Konon, wadian dadas pada mulanya didapat melalui ilham yang diperoleh seorang wanita bernama Ineh Ngundri Gunung. 
Pada zaman dahulu, apabila terjadi musibah atau panen tidak berhasil, orang Dayak Maanyan memerlukan wadian sebagai sarana melepas kesulitan. Salah satunya dengan menggunakan wadian dadas. Karena adanya pergeseran sosial dalam kehidupan masyarakat, maka wadian dadas yang semula sebagai sarana upacara berubah menjadi wadian dadas yang sampai sekarang diyakini dapat memberikan keselamatan bagi masyarakat Dayak Maanyan.

\section{Pertunjukan Tari Balian Dadas}

Tari Balian Dadas biasanya dibawakan oleh enam orang penari wanita dan dua orang penari laki-laki. Adegan awal dari tarian Balian Dadas ini dibuka oleh adegan dua orang penari wanita yang berperan sebagai dayang-dayang sang dukun. Mereka menggunakan baju warna kuning dengan hiasan daun sawan dan daun janur. Macam-

\section{Macam Tarian Daerah Kalimantan Tengah}

Macam - macam Tarian Daerah Kalimantan Tengah yang ada dan terdaftar sampai saat ini : Tari Dadas, Tarai Mangetem, Tari Pagar Ruyung, Tari Potong Pantan, Tari Wadian Amun Rahu, Tari Jarangkang Bangu, Tari Gelang Dadas dan Gelang Bawu (Iruang Wandrung), Tari Giring-giring, Tari Rantak Kipas Gempita, Tari Mandau, Tari Bahalai atau Tari Salendang Bawi, Tari Manasai(Usop, 2011).

\section{Karakter dan Pendidikan Karakter}

Karakter menurut pusat bahasa Depdiknas adalah "bawaan, hati, jiwa, kepribadian, budi pekerti, perilaku, personalitas, sifat, tabiat, temperamen, watak". Adapun berkarakter adalah berkepribadian, berperilaku, bersifat, bertabiat, dan berwatak".

\section{Pendidikan Karakter}

Penguatan pendidikan moral (moral education) atau pendidikan karakter(character education) dalam konteks sekarang sangat relevan untuk mengatasi krisis moral yang sedang melanda di negara kita. Krisis tersebut antara lain berupa meningkatnya pergaulan bebas, maraknya angka kekerasan anak-anak dan remaja, kejahatan terhadap teman, pencurian remaja, kebiasaan menyontek, penyalahgunaan obat-obatan, pornografi, dan perusakan milik orang lain sudah menjadi masalah sosial yang hingga saat ini belum dapat diatasi secara tuntas, oleh karena itu betapa pentingnya pendidikan karakter.

\section{Tujuan pendidikan karakter}

Tujuan pendidikan karakter adalah dasar manusia, yang bersumber dari nilai moral universal (bersifat absolut) yang bersumber dari agama yang juga disebut sebagai the golden rule. Pendidikan karakter dapat memiliki tujuan yang pasti, apabila berpijak dari nilai-nilai karakter dasar tersebut. Menurut para ahli psikolog, beberapa nilai karakter dasar tersebut adalah: cinta kepada Allah dan ciptaann-Nya (alam dengan isinya), tanggung jawab, jujur, hormat dan santun, kasih sayang, peduli, dan kerjasama, percaya diri, kreatif, kerja keras, dan pantang menyerah, keadilan dan kepemimpinan; baik dan rendah hati, toleransi, cinta damai, dan cinta persatuan. 


\section{Nilai-Nilai Pendidikan Karakter}

Agama: Masyarakat Indonesia adalah masyarakat beragama. Oleh karena itu, kehidupan individu, masyarakat, dan bangsa selalu didasari pada ajaran agama dan kepercayaannya (Eli Karliani, 2020). Pancasila: Negara Kesatuan Republik Indonesia ditegakkan atas prinsip-prinsip kehidupan kebangsaan dan kenegaraan yang disebut Pancasila. Pancasila terdapat pada Pembukaan UUD 1945 dan dijabarkan lebih lanjut dalam pasal-pasal yang terdapat dalam UUD 1945. Budaya: sebagai suatu kebenaran bahwa tidak ada manusia yang hidup bermasyarakat yang tidak didasari oleh nilai-nilai budaya yang diakui masyarakat itu. Tujuan Pendidikan Nasional: sebagai rumusan kualitas yang harus dimiliki setiap warga negara Indonesia, dikembangkan oleh berbagai satuan pendidikan di berbagai jenjang dan jalur.

\section{Disiplin}

Disiplin merupakan suatu sikap/perilaku yang pasti diharapkan oleh setiap pendidik agar kegiatan pembelajaran yang dilakukan baik di dalam kelas maupun di luar kelas dapat berjalan sesuai dengan yang diharapkan. Jika kita berbicara tentang disiplin maka pastilah kita memandang pada suatu peraturan, organisasi, kerja sama, dan lainnya. Tujuan kedisiplinan adalah sebuah aktivitas yang selalu dilakukan pastilah mempunyai suatu tujuan. Sama halnya dengan sikap disiplin yang dilakukan oleh seseorang. Orang melakukan sikap disiplin karena ia mempunyai suatu tujuan yang hendak dicapai setelah ia melakukan sikap tersebut.bertujuan agar siswa belajar hidup dengan pembiasaan yang baik, positif, dan bermanfaat bagi dirinya dan lingkungannya. Macam-macam disiplin menurut Oteng Sutrisno berdasarkan sifatnya dapat dibagi menjadi 2 yaitu: Disiplin positif merupakan suatu sikap dan iklim organisasi yang setiap anggotanya mematuhi peraturan-peraturan organisasi atas kemauannya sendiri.Mereka patuh pada tata tertib tersebut karena mereka memahami,meyakini dan mendukungnya. Disiplin Negatif, Yang dimaksud disiplin negatif di sini adalah suatu keadaan disiplin yang menggunakan hukuman atau ancaman untuk membuatorang-orang mematuhi perintah dan mengikuti peraturan hukuman. Pendekatan pada disiplin negatif ini adalah menggunakan hukuman pada pelanggaranperaturan untuk menggerakkan dan menakutkan orang-orang atau siswa lain sehingga mereka tidak akan berbuat kesalahan yang sama.

\section{METODE PENELITIAN}

Pendekatan penelitian yang digunakan dalam penelitian adalah kualitatif deskriptif karena dalam penelitian ini menghasilkan kesimpulan berupa data yang menggambarkan secara rinci, bukan data yang berupa angka-angka. Penelitian kualitatif adalah suatu pendekatan ilmiah yang mengungkap situasi sosial tertentu dengan mendeskripsikan kenyataan secara benar, dibentuk oleh kata-kata berdasarkan teknik pengumpulan analisis data yang relevan yang diperoleh dari situasi yang alamiah. Sesuai dengan penelitian kualitatif, kehadiran peneliti di lapangan adalah sangat penting dan diperlukan secara optimal. Peneliti merupakan instrument kunci utama dalam mengungkapkan makna dan sekaligus sebagai alat pengumpul data. Lokasi penelitian ini adalah Sanggar Igal Jue Palangka Raya. Sumber data utama yaitu berasal dari pelatih tarian dadas yang akan minta keterangan tentang makna tarian dadas bagi masyarakat 
Dayak Ngaju Kalimantan Tengah kemudian hasil wawancara di catat melalui catatan tertulis atau melalui perekaman video/audio dengan camera HP. Pengumpulan data yang digunakan dalam penelitian ini adalah sebagai berikut: observasi, wawancara, studi kepustakaan dan dokumentasi. Sedangkan teknik penggunaannya dapat dijelaskan sebagai berikut : Observasi, Wawancara, Studi Kepustakaan, Dokumentasi. Penelitian ini menggunakan teknik analisa data kualitatif, data di olah sehingga dapat di ambil kesimpulan atau makna yang valit, serta metode yang sebaiknya untuk menganalisis data kualitatif agar dapat memenuhi syarat ilmiah dalam penelitian. Adapun keempat kriteria yang digunakan sesuai (Lexy Moleong 2002: 173) adalah sebagai berikut : Derajat kepercayaan, Keteralihan, Kebergantungan, Kepastian

\section{HASIL DAN PEMBAHASAN}

1. Makna tarian dadas dalam pembentukan karakter disiplin anak pada sanggar Igal Jue Palangka Raya

Tarian dadas adalah salah satu sarana upacara dalam bidang pengobatan tradisional pada masyarakat Suku Dayak Ma'anyan di Kecamatan Dusun Timur, Kabupaten Barito Timur, Provinsi Kalimantan Tengah. Konon, wadian dadas pada mulanya didapat melalui ilham yang diperoleh seorang wanita bernama Ineh Ngundri Gunung. Wanita tersebut mendapatkan ilham untuk menjalankan suatu tugas dari seorang dewa untuk menyembuhkan seseorang atau apa yang diperintahkan oleh dewa. Wanita ini merupakan wadian yang pertama dan merupakan utusan dewa yang diwujudkan dalam bentuk burung elang, selanjutnya wadian akan diteruskan oleh keturunan berikutnya.

2. Nilai-nilai yang terkandung dalam tarian dadas dalam pembentukan karakter disiplin pada Sanggar Igal Jue Palangka Raya

Tari Balean Dadas adalah tarian tradisional yang berasal dari suku Dayak yang ada di Provinsi Kalimantan Tengah. Tari ini berasal dari tradisi ritual dukun di pedalaman Kalimantan Tengah dalam upaya meminta keberkahan Tuhan dan penyembuhan bagi penduduk yang sakit. Penulis mencoba mengajak kita untuk mengenal lebih jauh mengenai seni tradisi tari Balean Dadas yang berasal dari Kalimantan Tengah, sehingga bisa menambah wawasan kita semua dalam hal seni tari khususnya tari daerah Indonesia.

3. Faktor pendukung dan penghambat pembentukan karakter disiplin anak pada sanggar Igal Jue Palangka Raya

Karakter anak sanggar igal Jue juga terlihat dalam pelaksanaan Latihan. Hal tersebut dapat terlihat pada upaya pelatih untuk membimbing peserta anak sanggar untuk melakukan kegiatan-kegiatan pembelajaran yang berdimensi nilai-nilai karakter bangsa yang mereka cerminkan dalam kegitan ekstrakurikuler yang mereka lakukan di sanggar igal jue.

Berikut ini faktor pendukung dan penghambat pembentukan karakter disiplin anak pada sanggar Igal Jue Palangka Raya :

a. Yang menjadi faktor pendukungnya adalah kemaun mereka yang mau berlatih dari yang tidak tau menjadi tau dari yang tidak bias sampai bias melakukan 
gerakan walau pun memrlukuan waktu yang lama dfalam berlatih. Karena dalam tarian itu ada pembagian jenis gerak dan karakter dari gerak itu sendiri.

b. Faktor penghamabat ketika sianak tidak mau lagi latihan sehingga kesulitan dalam memberikan binaan terhadap anak sanggar yang kuarang aktif sebab dalam mementaskan tarian dadas harus totalitas serta penghayatan yang baik dan berkerakter serta disaiplin.

\section{E. KESIMPULAN}

Dari beberapa uraian bab IV sebelumnya, maka ditarik kesimpulan sebagai berikut. Makna tarian dadas dalam membentuk karakter disiplin yang melakuklan tarian dadas disitu sudah tentu jika tidak disiplin dalam melakukan latihan tarian itu tidak bisa dilakukan harus mempunyai konsentari yang tinggi dalam menari untuk menyesuaikan irama dan gerak sehingga mau tidak mau anak sanggar secara tidak langsung melatih karakter disiplin dalam melakukan latihan. Nilai-nilai yang terkandung dalam tarian dadas adalah nilai magis, nilai seni budaya, nilai pesan sejarah, nilai karakter dan nilai estetika keindahan dan keunikan dalam tarian dan music. Sehingga penari tarian dadas haru mempunyai sikap dan karakter yang baik sehat jasmani dan rohani jika tidak maka, kesan lain bisa masuk karena mempunyai nilai - nilai megis. Faktor pendukung pemebentukan karakter disiplin adalah jadwal yang di buat dan disepakati bersama sebab setiap anggota tim, harus disiplin waktu dan juga mempunyai komitmen. Kemudian faktor penghambat ketika ada anggota yang tidak disiplin dan sulit menghapal karakter yang ia pegang serta gerakan dan kesesuaian anatara gerak dan music.

\section{F. SARAN DAN UCAPAN TERIMA KASIH}

1. Hendaknya anak sanggar igal jue Palangka Raya selalu disiplin dalam berlatih sehingga menciptakan karakter disipilin yang baik.

2. Adanya kerjasama yang baik dari pihak yang bertanggung jawab atas pelestarian seni budaya seperti Kepala Adat, serta tokoh Masyarakat dan perhatian pemerintah atas pelaku seni.

3. Untuk semua masyarakat supaya mamupu memberikan pemahaman kepada anak tentang pentingnya seni budaya kalimantan tengah.

4. Pemberian dan pengajaran karya seni budaya kalimantan tengah sejak dini dan harus dimasukan dalam kurikulum belajar.

\section{REFERENSI}

Bistak, Sirait, 2008, http://oreniffmilano,wordpress,com/2009/04/03/ pengaruh di siplinbelajar - lingkungan - keluarga - sekolah - terhadap - prestasi - belajar-siswa.

Eli Karliani, A. S. (2020). The Integration of Islamic Education Value in Strengthening Higher Education Students' Peace-loving Character. ICIE (International Conference on Islamic Education , 19-24. 
Eva Isdayanti, E. L. (2020). Strategi Merawat Kerukunan Dalam Keberagaman Masyarakat di Desa Pantai Harapan Kecamatan Cempaga Hulu Kabupaten Kotawaringin Timur. Jurnal Pendidikan Ilmu Pengetahuan Sosial (JPIPS) , 16-21.

Departemen Pendidikan Nasional, 2010, Pendidikan Karakter Teori $\mathcal{E}$ Aplikasi, Jakarta: Direktorat Jenderal Manajemen Pendidikan dan Menengah Kementerian Pendidikan Nasional.

Ibrahim Offeny. 2014, Seni Budaya Kalimantan Tengah, Jenggala Pustaka Utama. Surabaya. Jazuli,M.1994. Telaah Teoretis Seni Tari. Semarang:IKIP Semarang Press.

Karliani, E., Lion, E., \& Sakman, S. (2018). Huma Betang Philosophy as the Solidarity Prototype and Ethnic Conflict Prevention in Dayak Communities of Central Kalimantan. https://doi.org/10.2991/acec-18.2018.90

Milawaty, Eki. 2015. Meningkatkan Sosial Emosional Anak Melalui Seni Tari Kreasi di Kelompok B pada TK Negeri Pembina Sipatana Kota Gorontalo. Jurusan PAUD Fakultas Ilmu Pendidikan Universitas Negeri Gorontalovol. 3, no.3

Ni Made, R. (2015). Membongkar Makna Pertunjukan Tari sang Hyang Dedari di Puri saren Agung Ubud, Bali pada Era Global. Mudra Jurnal Seni Budaya.

Nursyam, Y., Nasution, H., Yeni, F., \& Anggraini, N. (2016). PEMBINAAN KREATIVITAS SENI TARI PADA SISWA SMPN 2 KOTA BUKITTINGGI. Batoboh. https://doi.org/10.26887/bt.v1i1.124

Restuningrum, A. (2017). Nilai Dan Fungsi Tari Lenggang Nyai. Seni Tari.

Riantri, E. T. (2019). MAKNA IKINSAI DALAM MIEMPU BUYUK SUKU DAYAK MA'ANYAN. Joged. https://doi.org/10.24821/joged.v12i2.2542

Riwut Nila, 2003. Maneser Panatau Tatu Hiang, Menyelami Kekayaan Leluhur. Pusakalima Palangka Raya.

Sugiyono (2012) Metode Penelitian Pendidikan Pendekatan Kuantitatif, Kualitatif, dan R $\mathcal{E}$ D Alpabeta Bandung

Soedarsono.R.M. (2010). Seni Pertunjukan Indonesia di Era Globalisasi. Yogyakarta: Gadjah Mada University Press.

Suwaji. (2012). Jurnal seni tari. JOGED Jurnal Seni Tari.

Suyanto. (2009). Urgensi Pendidikan Karakter. Direktorat Jendral Pendidikan Dasar Kementrian Pendidikan Nasional.

Usop, T. B. (2011). Kearifan Lokal Dalam Arsitektur Kalimantan Tengah Yang Berkesinambungan. Jurnal Perspektif Arsitektur. https://doi.org/https://www.researchgate.net/profile/Tari_Usop/publication/3347 31766_KEARIFAN_LOKAL_DALAM_ARSITEKTUR_KALIMANTAN_TENGA H_YANG_BERKESINAMBUNGAN/links/5d3dc3bba6fdcc370a67d59b/KEARIF AN-LOKAL-DALAM-ARSITEKTUR-KALIMANTAN-TENGAH-YANGBERKESINAMBUNGAN.pdf 